\section{Breast-milk substitutes}

SIR

In May 1981, the World Health Assembly broke new ground by overwhelmingly approving an International Code of Marketing of Breast-milk Substitutes. The Code calls for a ban on the advertising of powdered baby milks or other products as a partial or total replacement for breast milk, as well as a ban on the distribution of samples of these products to parents.

This Code was considered vitally important by the 118 nations who recommended it at the World Assembly. They recognised that 'in view of the vulnerability of infants in the early months of life and the risks involved in inappropriate feeding practices ... the marketing of breast-milk substitutes requires special treatment, which makes usual marketing practices unsuitable for these products'.

Despite this, many companies continue indiscriminately to promote their products, while health authorities turn a blind eye. A recent example occurred in the December 1983 issue of Mother magazine, which had a front-cover promotion for Milupa's Infant Drink, including a free sample stuck on the cover. Milupa recommended the use of this fennel and glucose drink 'from one week onwards'.

There is no scientific evidence to suggest that breast-fed infants require additional fluids to satisfy thirst. Drs Jelliffe and Jelliffe (1) go so far as to suggest that human milk 'appears to be designed as a "supply-and-demand" source of nutrients and water, in response to both hunger and thirst'. The Department of Health and Social Services (DHSS) notes, in Present Day Practice in Infant Feeding: 1980, that 'glucose water, or any other fluid, is unnecessary during the neonatal period ...' and expresses some concern that the early introduction of fluids can interfere with the initiation and maintenance of breast-feeding.

Mother magazine has a circulation of just over 72,000 in the United Kingdom, and approximately 1,350 copies overseas. It is read in such countries as New Zealand and Malaysia. Through this indiscriminate promotion, Milupa is subjecting mothers, not only in the UK but also abroad, to unnecessary pressure to introduce a form of bottlefeeding.

Although this form of marketing is prohibited by the World Health Organisation's (WHO) international code, it is not prohibited by a voluntary code issued by the DHSS for the UK. The UK code was drawn up by the Food Manufacturers Federation (FMF), while the WHO code was prepared by scientific experts more concerned with the protection of infant health than with the protection of sales.

The WHO code noted that health professionals have 'an essential role to play in guiding infant feeding practices, encouraging and facilitating breastfeeding, and providing objective and consistent advice. . .'That role, surely, must also include exerting pressure on health authorities to ensure that the UK code is brought into line with the international standard and that this type of marketing practice is stopped.

\section{Reference}

(1) Jelliffe D B, Jelliffe E F P. Human milk in the modern world. London: Oxford University Press, 1978: 45.

ANDY CHETLEY War on Want, 467 Caledonian Road, London N7 9BE

'Sympathy' or 'empathy'? SIR With reference to the article by Gregory E Pence, Can Compassion be taught?, JME Vol 9 No 4, December 1983: 'sympathy' or 'empathy'? the activating requirement for both is feeling plus imaginative ability. Like 'insight' and 'intuition', empathy (prefix 'em' $\rightarrow$ 'en' $\rightarrow$ 'in') transcends the quality of sympathy by virtue of higher imaginative power and absence of 'self'. Its original meaning has become debased through association with the idea of 'projection of the self into the feelings of others. Empathy is more precisely sensitive receptivity to the suffering of another or others through available data; and awareness, understanding and experience of humanity and human suffering. Projection is involved, but like 'aß truism' need not connote 'the self Rather it is an intuitive leap of mind and feeling which encompasses all the aspects of and the condition of the sufferer, and in this respect achieves a deeper insight than sympathy, which is limited by the prefix 'sym' $\rightarrow$ 'syn' $=$ 'like'.

\section{JESSE CATO DANIEL \\ Ducks Foot House, Bush Green, Pulham Market, Diss, Norfolk}

